\title{
Diretrizes de projeto com enfoque nos afetos e na memória positiva orientada à sustentabilidade
}

Myrla Lopes Torres é Professora do quadro permanente da Universidade Federal da Paraíba, graduada em desenho industrial pela Universidade Federal de Campina Grande, especialista em ergonomia pela Universidade Federal de Pernambuco, mestrado na área de ambiência e conforto térmico pela Universidade Federal de Campina Grande e Doutoranda em Design pela Faculdade de Arquitetura da Universidade de Lisboa. <myrla.torres@@academico.ufpb.br> ORCID: 0000-0003-4335-3722
Resumo Estudar, compreender e aplicar a sustentabilidade é imprescindível no contexto de ensino e aprendizagem relativo ao projeto de produto. É notório que os princípios do desenvolvimento sustentável podem auxiliar na redução de impactos ao meio ambiente e impulsionar mudanças sociais, ambientais e econômicas. Todavia, os aspectos subjetivos relacionados à sustentabilidade ainda são preteridos. Neste trabalho foi realizada uma revisão bibliográfica sobre a relevância dos vínculos afetivos, a sistematização de diretrizes de projetos que podem suscitar os afetos e a memória positiva na relação entre usuários e artefatos, bem como uma pesquisa pré-experimental de ensino e aprendizagem em uma disciplina de projeto de produto 2, em um curso de Design.

Palavras chave Design. Ensino e Aprendizagem. Projeto. Sustentabilidade. Afetividade. 


\section{Project guidelines with a focus on affections and positive memory oriented towards sustainability}

Abstract Studying, understanding and applying sustainability is essential in the
context of teaching and learning about product design. It is well known that the
principles of sustainable development can help to reduce impacts on the envi-
ronment and promote social, environmental and economic changes. However,
subjective aspects related to sustainability are still overlooked. In this work, a
bibliographic review was carried out on the relevance of affective bonds, the sys-
tematization of project guidelines that can elicit affections and positive memory
in the relationship between users and artifacts and a pre-experimental research
on teaching and learning in a project discipline of product 2 in a Design course.

Keywords Design. Teaching and Learning. Sustainability. Affectivity.

\section{Directrices de proyectos enfocados a afectos y memoria positiva orientados a la sustentabilidad}

Resumen Estudiar, comprender y aplicar la sostenibilidad es fundamental en el contexto de la enseñanza y el aprendizaje relacionados con el diseño de productos. Es bien sabido que los principios del desarrollo sostenible pueden ayudar a reducir los impactos sobre el medio ambiente y promover cambios sociales, ambientales y económicos. Sin embargo, todavía se pasan por alto aspectos subjetivos relacionados con la sostenibilidad. En este trabajo se realizó una revisión bibliográfica sobre la relevancia de los vínculos afectivos, la sistematización de lineamientos de proyectos que pueden suscitar afectos y memoria positiva en la relación entre usuarios y artefactos, así como una investigación pre-experimental sobre la enseñanza y el aprendizaje en una disciplina de diseño de producto 2 , en un curso de Diseño.

Palabras clave Diseño. Enseñando y aprendiendo. Proyecto. Sustentabilidad. Afectividad. 


\section{Introdução}

$\mathrm{Na}$ contemporaneidade se vive a proliferação de informações, a busca por resultados rápidos e a substituição imediata do produto. Absorvido por essa ansiedade de respostas, como contribuir para que as ações do presente não deixem sequelas para as futuras gerações? Como ter empatia sem ter tempo disponível? Como falar em inovação sem mencionar o impacto ambiental? Essas são questões que precisam ser refletidas no ensino e na aprendizagem em design de produto. As mudanças de paradigmas vêm acontecendo a partir da incorporação dos princípios da sustentabilidade, da conscientização sobre o consumo, da valorização dos aspectos humanos, do trabalho colaborativo e dos significados aos artefatos.

Segundo Kazazian (2005, p. 28): "Em 1990, um americano da classe média consumia um volume de energia equivalente ao de 3 japoneses, 6 mexicanos, 14 chineses, 38 indianos, 168 bengaleses, ou ainda 531 etíopes". O caminho para a sustentabilidade é imprescindível e deverá acontecer entre erros e contradições, que promovam o reconhecimento da necessidade "de viver melhor consumindo (muito) menos e regenerando a qualidade do ambiente" (MANZINI, 2008, p. 26). Ademais, "Mudança climática, esgotamento de recursos, instabilidade potencial dos ecossistemas e a erosão da capacidade ecológica são alguns dos sintomas manifestos desta tendência de consumo" (FUAD-LUKE, 2009. p. 67, tradução nossa). Nesse mesmo sentido, Thackara ressalta que:

\footnotetext{
Oitenta por cento do impacto ambiental dos produtos, serviços e infraestruturas ao nosso redor é determinado no estágio de design. As decisões de projeto moldam os processos por trás dos produtos em uso, materiais e energia necessários para produzi-los, a maneira como os operamos diariamente e o que acontece quando eles não precisam mais deles. Podemos não ter pretendido fazê-lo, e podemos nos arrepender da maneira como as coisas acabaram, mas criamos nosso caminho para as situações que nos enfrentam hoje (tradução livre THACKARA, 2008. p. 1).
}

Acredita-se que é preciso refletir sobre os estilos atuais de vida, promover a sustentabilidade, considerando os princípios do desenvolvimento sustentável, pensar sobre a geração de resíduos, compreender os vínculos afetivos na relação entre usuários e artefatos, bem como reconhecer a relevância dos afetos e da memória positiva. Ademais, "perceber que o ciclo de vida de qualquer artefato estende-se para muito além do seu uso primeiro e mesmo o seu descarte" (CARDOSO, 2012, p. 88) pode auxiliar na conscientização de projetos orientados à sustentabilidade. 


\section{Objetivos}

Este trabalho consiste em um substrato de uma tese de doutorado em design, desenvolvida pela Faculdade de Arquitetura da Universidade de Lisboa. $O$ objetivo geral da pesquisa aborda a relevância dos vínculos afetivos entre usuários e os artefatos como estratégia para fomentar atitudes responsáveis orientadas à sustentabilidade no design de produtos. Para este texto foi feito um recorte com embasamento teórico sobre a sustentabilidade respaldada nos sentimentos, a sistematização de diretrizes de projetos, que podem identificar os vínculos afetivos e uma pesquisa pré-experimental de ensino e de aprendizagem em uma disciplina de projeto de produto 2 , em um curso de Design em uma universidade pública no Brasil.

\section{Metodologia}

Esta investigação tem como principal característica de classificação, ser de finalidade aplicada, de objetivo exploratório, de natureza experimental, com uma abordagem predominantemente qualitativa, apenas com constatações quantitativas nas discussões relacionadas às respostas aos questionários aplicados, compreendendo os seguintes procedimentos:

1. Pesquisa bibliográfica referente ao estudo de textos sobre a sustentabilidade respaldada nos sentimentos, que possibilitou a sistematização de diretrizes de projeto para a identificação de vínculos afetivos entre os usuários e os artefatos;

2. Sistematização de diretrizes de projeto, com base nos princípios da sustentabilidade (PAPANEK, 1971; MANZINI; VEZZOLI, 2002), respaldada nos sentimentos (DESMET, 2002; CHAPMAN, 2005; BORJESSON, 2006; WALKER, 2006; RUSSO, 2010; MCDONAGH, 2017);

3. Pesquisa pré-experimental desenvolvida com um único grupo, sem controle anterior, no contexto de ensino e de aprendizagem em uma disciplina de projeto de produto 2, em um curso de design de uma universidade pública. Foram realizadas 15 aulas de 04 horas semanais, com um grupo de 31 estudantes, dentre esses 02 alunos se afastaram das atividades por problemas de saúde e 03 alunos compareceram a poucos encontros, totalizando a participação efetiva de 26 estudantes;

4. Os resultados e as discussões foram realizados a partir da interpretação dos painéis desenvolvidos pelos estudantes e das respostas aos questionários. A interpretação dos painéis foi executada pela autora 
deste trabalho, levando em consideração os aspectos subjetivos, que visam os afetos e a memória positiva orientados à sustentabilidade e à evidência do uso das diretrizes de projetos, que podem levar a promover vínculos afetivos entre os usuários e os artefatos. 0 questionário foi elaborado para obter informações sobre os conhecimentos adquiridos, os sentimentos envolvidos e a compreensão sobre as diretrizes do projeto. Essa técnica de investigação foi proposta de modo auto-aplicado, permitindo o anonimato e evitando a influência das opiniões alheias e exposição desnecessária dos estudantes. Nos questionários estavam disponíveis questões fechadas e questões aberta com a escala Likert: 1 correspondendo ao nível de satisfação mínimo e 5 indicando o nível de satisfação máxima e uma análise qualitativa, de acordo com as respostas abertas. Foram aplicados na última aula e 20 estudantes responderam.

\section{Afetividade, Memória e Sustentabilidade}

Os artefatos são envolvidos pelo sentimento humano e são construídos, compreendidos e reconhecidos pelas pessoas quando usados (Krippendorff, 2000). "Sem um sujeito capaz de atribuir significado, o objeto não quer dizer nada; ele apenas é" (CARDOSO, 2012. p. 33). As coisas não são apenas artigo de sobrevivência e conforto, elas estão imbuídas de significados, "que manifestam habilidades e moldam as identidades" (CSIKSZENTMIHALYI; ROCHBERG-HALTON, 1981. p. 1). Ademais,

\footnotetext{
Para entender o significado de um artefato com qualquer profundidade é preciso saber o que já se passou com ele ou, no caso de um artefato móvel, por onde ele passou. A existência de qualquer objeto decorre dentro de um ciclo de vida que comporta desde sua criação até sua destruição. Quanto mais tempo ele consegue resistir - ou seja, manter-se íntegro e reconhecível - maior será a chance de incidirem sobre ele mudanças de uso e de entorno (CARDOSO, 2012. p. 35).
}

O estudo do percurso dos artefatos permite compreendê-los como possuidores de vida social. A análise da sua circulação em um contexto social é realizada pela sua biografia, indicando o seu surgimento, envelhecimento e descarte (APPADURAI; KOPYTOFF, 1986). Durante a circulação 
das coisas são atribuídos significados que constroem a biografia dos objetos (KOPYTOFF, 1986). Os valores interpretados pelas pessoas com relação aos artefatos são resultados de um juízo de valor (APPADURAI, 1986).

Os significados são reconhecidos a partir da percepção e da interpretação de seus aspectos visuais, que marcam o tempo e traduzem identidades. "Esta auto-imagem reflectida nos objectos constitui um guia e um ponto de referência para o grupo, tendo em vista o futuro, e acaba por se transformar no retrato doada à posteridade" (KUBLER, 1998. p.22).

As coisas refletem o retrato de uma identidade coletiva por uma sequência temporal intermitente e variável, que pode ser compreendida pelos conceitos de cabeça de série ou obra inaugural e série formal ou conjuntos de réplicas. A categoria forma-classe prevê a manutenção de formas que indicam nova possibilidades, revelando o método genealógico ancorado em Focillon (KUBLER, 1998).

A análise da genealogia da forma possibilita a verificação do desenvolvimento, ocorrida em determinado artefato durante o tempo. Permite-se, também, a observação das alterações e as suas atualizações promovidas pelo progresso, pela tecnologia e pela percepção das pessoas. É o estudo genealógico que pode indicar formas arquetípicas reconhecidas por grande parte das pessoas. "Um arquétipo dominante necessita de uma forma capaz de transmitir o que faz, e o que o usuário precisa fazer para que ele funcione" (SUDJIC, 2010. p. 57). 0 arquétipo transmite familiaridade, é usado pela intuição e comunica emoções.

O estudo da trajetória dos objetos pela sua biografia, a análise da genealogia da forma e o reconhecimento do arquétipo podem indicar as informações essenciais que suscitem afetos e memória positiva.

Acredita-se que a relação entre usuário e artefato envolvida com sentimentos pode proporcionar um consumo consciente, na medida em que os desejos e as necessidades dos usuários são contemplados além das funções práticas, alcançando o subjetivo, o inatingível e a imaterialidade. Para Papanek (1995), esse seria o lado espiritual do design, configurado pela ética e moral do designer e do modo como o objeto é usufruído. Evidentemente, continua-se enfatizando a necessidade de se respeitar os princípios do desenvolvimento sustentável, avaliando-se a seleção dos recursos naturais, adotando-se uma produção limpa, programando montagem e transporte eficientes, enfim, seguindo o que foi preconizado por Papanek desde 1970. Além disso, são acrescentados critérios que abordem os afetos e a memória positiva como componentes para a responsabilidade ambiental.

"O afeto é o segmento da atitude que se refere ao sentimento e às emoções" (ROBBINS, 2005). O afeto é acionado em virtude da atenção despertada e motivada por algo ou alguém. A emoção ocorre por dispositivos sensoriais e é desenvolvida por ações sucessivas que são processadas quimicamente no corpo. É possível reconhecer as emoções sentidas pelas pessoas, pois são orientadas para o exterior. Já os sentimentos são processados mentalmente. É possível ter os sentimentos e não os demonstrar. As 
emoções geram sentimentos, ou seja, ter emoções significa ter sentimentos, mas nem todo sentimento é gerado por emoções (DAMÁSIO, 2011). Nesse sentido, o "valor emocional - de caráter subjetivo - incorpora motivações afetivas ligadas às percepções sensoriais" (KRUCKEN, 2009. p. 27).

As emoções e os sentimentos influenciam na memória, que é a capacidade de armazenamento de imagens geradas pelo cérebro (DAMÁSIO, 2004). Assim, "lembrar uma pessoa ou evento, ou contar uma história, requer a evocação; reconhecer objetos a nossa volta também" (DAMÁSIO, 2009. p. 173). Do mesmo modo, a "memória é a experiência deslocada do seu ponto de partida na vivência imediata [...] quase tudo que somos e pensamos depende da memória" (CARDOSO, 2012. p. 39).

Diante disso, acredita-se ser essencial compreender a afetividade preservada na memória, para suscitar sentimentos e emoções que permitam uma relação mais sincera e duradora entre usuários e artefatos. É possível que a durabilidade seja ocasionada apenas pelo valor afetivo e que "o proprietário adquire consciência de que o valor do objeto vai durar para além do ínterim em que está em suas mãos" (CARDOSO, 2012. p. 92). Reconhecer os motivos que suscitam os afetos e a memória positiva na relação entre usuário/artefato e aplicá-los no desenvolvimento de projetos pode ser uma nova abordagem sustentável, que não se distancia dos já preconizados princípios do eco design, mas engloba aspectos subjetivos à sustentabilidade.

Pessoas, artefatos e afetividades são objetos de estudos de alguns trabalhos, tais como: "Emotionally Durable Design" (CHAPMAN, 2005); "Affective Sustainability" (BORJESSON, 2006); "The experience of love for products" (RUSSO, 2010); "Designing Emotions" (DESMET, 2002), "Designing sustainability" (WALKER, 2014) e "Emotional sustainability" (MCDONAGH, 2017).

Chapman (2005) explora os motivos pelos quais os usuários descartam os produtos e investiga algumas estratégias para prolongar sua vida útil, chamando atenção para o fato de que o design, pela emoção, possa ser durável. "Emotionally Durable Design" tem como objetivo conscientizar o consumo pela durabilidade na relação entre usuário e produto. Para Van Krieken et al. (2012), muitas estratégias estão sendo elaboradas e publicadas, porém, pouco utilizadas na prática.

Borjesson (2006) acredita que o objeto deve ter competência afetiva para ser sustentável. "Affective Sustainability" é uma experiência vivida, processada no nível inconsciente e relevante para o ser humano, fazendo com que o tempo não seja determinante; as tradições sejam valorizadas; explorem as necessidades e as raízes do usuário; possibilitem uma estética agradável sem exigência de padrões e preservem a intuição no processo projetual.

Russo (2010) aborda o amor entre produtos e usuários. Para a autora, os laços pessoais entre indivíduos e os artefatos são semelhantes ao amor entre parceiros e deve ocorrer por: uma interação fluída, envolvendo processos cognitivos e emocionais; resgate da memória afetiva, bem como prazer social e físico, a partir de significados relevantes para o usuário. 
Walker (2014) faz críticas sobre a estética dos produtos contemporâneos, demonstrando que é possível reconhecer práticas de projeto e produção insustentáveis pela sua estética. $O$ autor acredita que os artefatos precisam transmitir significados humanos e que para projetar para a sustentabilidade se faz necessária a ética e a espiritualidade, permitindo que a estética transcenda a aparência e o estilo. Ao falar em valores espirituais no design, Walker resgata a visão de Papanek sobre a importância dos valores espirituais humanos para efetivar um design responsável que ofereça bem-estar à sociedade. Pantaleão (2017) afirma que, para ambos os autores, o relevante é a noção sobre significado e propósito do projeto, ressaltando que o design para a sustentabilidade é visualizado a partir da teoria, da prática, da estética e da ética em plenitude "regidos por um princípio imaterial: a consciência moral/espiritual" (PANTALEÃO, 2017. p. 30).

McDonagh (2017) reflete sobre os aspectos práticos da sustentabilidade, enfatizando que a qualidade do material não se traduz em longevidade do produto e que por ser reciclado pode não ser aceitável para o meio ambiente. "Emotional sustainability" considera que a utilização de material reciclado não prolonga necessariamente a vida útil do produto. $O$ autor reforça que o produto deve oferecer significados, uma experiência produtiva e que proporciona momentos enriquecedores.

Ainda foi possível verificar em alguns estudos a sistematização de critérios de projeto que podem auxiliar na configuração dos vínculos afetivos na relação entre usuário/objeto, tais como:

- As regras descritas por Arguin (2010) são baseadas no conceito de Chapman (2005): pense no consumidor; inclua o consumidor no processo; valorize as necessidades dos usuários; design para educar; design para individualidade; seja criativo e único.

- A competência afetiva, elaborada por Borjesson (2006), prevê que, para desenvolver um objeto, deve-se considerar: um modo de interagir com as experiências vividas anteriormente; reconhecer as tradições e as promover como experiências; apreciar a simplicidade dos elementos visuais; compreender os componentes afetivos e cognitivos e estabelecer o vínculo com o passado, que permita que o produto se mantenha vivo no futuro.

- De acordo com Van Krieken et al. (2012), as qualidades para os produtos emocionalmente duráveis são: envolvimento, animação, adaptação à auto-identidade, evocação memórias e ser gratificante.

- "Framework emotional durability design nine - a tool for a product longevity", desenvolvido por Haines; Gadd; Chapman et al. (2018) identifica alguns motivos pelos 
quais os objetos não são descartado: relacionamentos de estabilidade e confiabilidade com o produto; narração de histórias, que evocam memórias e refletem as tradições; identificação entre usuário/artefato; possibilidades de imaginação pelo sentimento de amor; interação usuário e artefato; reconhecimento da "alma" ao objeto; que tenha qualidade e durabilidade; provoque prazer e boas sensações durante o percurso de seu envelhecimento e promova adaptações.

- "Designing emotions that last", formulada por Sogutly e Desmet (2019), prevê diretrizes para a prática projetual que criem vínculos emocionais duradouros, baseada em: envolvimento usuário/produto; variedade funcional; adequação ao tempo; refletir necessidades; variedade comportamental; variedade sensorial e suscitar memórias.

Em suma, a afetividade pode ser percebida com relação: à durabilidade e longevidade dos artefatos (CHAPMAN, 2005); ao envolvimento afetivo transmitido pelo tempo, pela tradição ou pela estética (BORJESSON, 2006); à experiência de amor promovida pelos artefatos (RUSSO, 2010); à comunicação de significados humanos (WALKER, 2014); à experiência produtiva e aos momentos enriquecedores (MCDONAGH, 2017). A compreensão sobre os significados pode ser investigada pela análise da genealogia da forma (KUBLER, 1998); da análise de circulação dos artefatos em um contexto social realizado pela biografia dos objetos do cotidiano, indicando o seu surgimento, envelhecimento e descarte (APPADURAI; KOPYTOFF, 1986).

As considerações sobre o desenvolvimento de projeto de produto para a sustentabilidade ressaltando os aspectos subjetivos, não desconsideram os aspectos objetivos. Em suma, continua-se seguindo os princípios para o desenvolvimento sustentável, tais como:

- selecionar matérias-primas renováveis, refugos de produção ou material reciclado;

- utilizar tecnologia para a produção de baixo impacto;

- reduzir o uso de energia durante a fabricação do produto ou utilizar energia renovável;

- utilizar materiais e processos de fabricação locais;

- racionar o uso de água na produção;

- evitar inserir substâncias tóxicas ou danosas no produto;

- evitar o uso de materiais não-renováveis ou em extinção;

- aproveitar os resíduos que seriam descartados;

- reduzir a quantidade de componentes; 
- evitar excesso de materiais;

- utilizar a menor quantidade de material possível;

- fazer projetos que utilizem a menor quantidade de materiais, componentes e fixações possíveis;

- reduzir as etapas de produção;

- facilitar a montagem das estruturas;

- priorizar produtos modulares, multifuncionais, desmontáveis, empilháveis e dobráveis;

- possibilitar ajustes, consertos e substituições de peças;

- projetar embalagens compactas;

- facilitar o transporte, se possível com recursos renováveis.

- Os princípios citados somados às diretrizes de projeto, elaboradas com base nos estudos citados, que ressaltam os aspectos subjetivos do projeto, visando afetos e memória positiva e relacionam a sustentabilidade e os vínculos afetivos (Figura 01).

- A aplicação das diretrizes de projeto pode permitir:

- reconhecer as reais necessidades e desejos das pessoas;

- identificar uma oportunidade de design, que possibilite o bem-estar das pessoas;

- estudar os princípios do desenvolvimento sustentável e avaliar os itens adequados para o contexto;

- considerar as questões práticas, estéticas, simbólicas e sentimentais dos objetos, visando aos aspectos objetivos e subjetivos da sustentabilidade;

- coletar informações sobre as pessoas, envolvendo-se no cotidiano delas;

- perceber a identidade absorvida e transmitida pelo usuário pelo objeto, configurando o objeto como um espelho;

- reconhecer os vínculos afetivos entre pessoas e artefatos;

- compreender o perfil dos envolvidos e antecipar cenários de futuro;

- ativar os valores e os significados transmitidos pelos objetos;

- analisar a trajetória de vida do objeto em posse do usuário, produzindo, assim, uma biografia sobre o objeto;

- compreender a evolução do objeto, a partir da sua genealogia da forma;

- reconhecer os sentimentos envolvidos na relação entre usuário e artefatos; 
- privilegiar aspectos visuais que permitam que o usuário se identifique e que suscite afetos e memória positiva;

- executar as diretrizes de projetos que ressaltem os aspectos subjetivos, visando afetos e memória positiva.

Fig 1. Diretrizes de projeto visando afetos e memória positiva Fonte: Autor (2020)

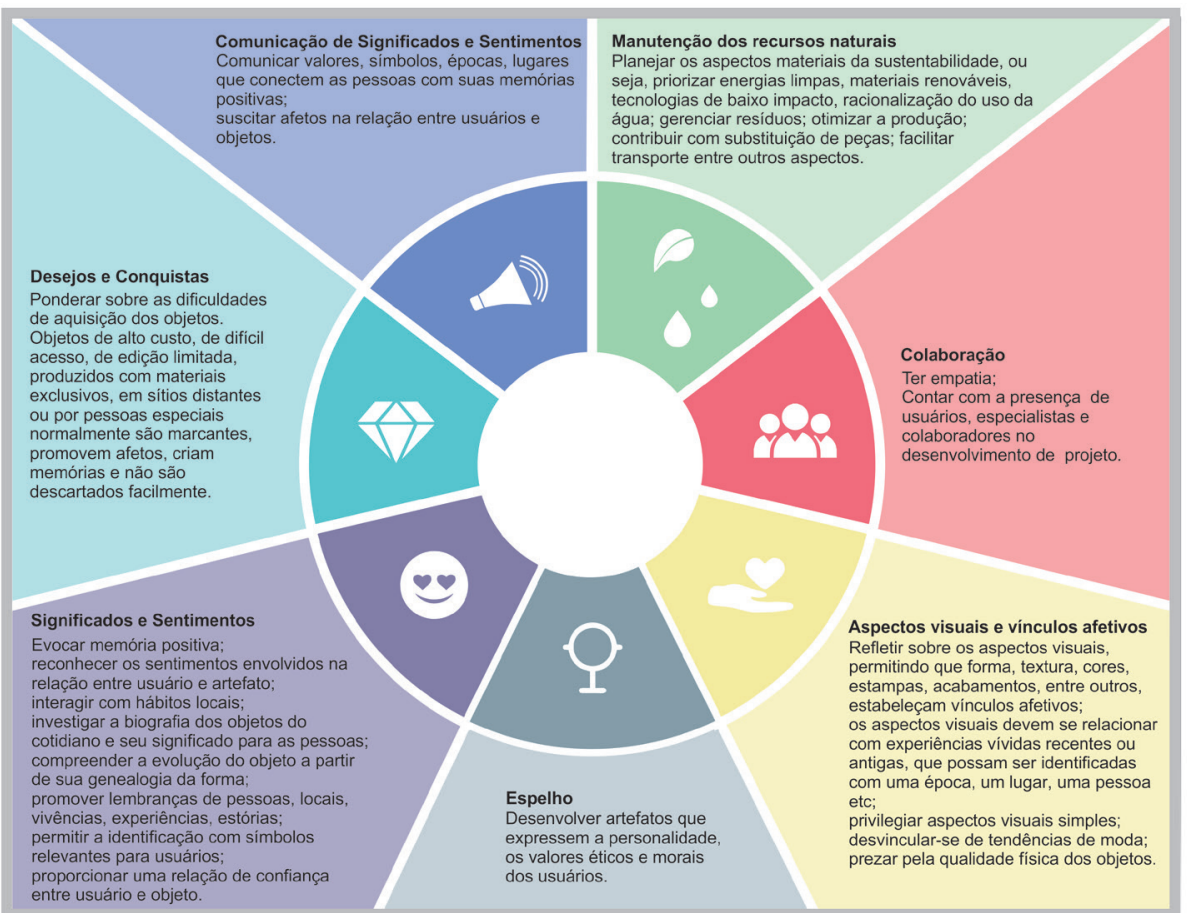

As diretrizes de projetos relacionadas aos vínculos afetivos colaboram com os aspectos sociais, econômicos e ambientais. Com relação ao social, aborda-se o caráter humano da sustentabilidade, possibilitando que o indivíduo seja observado nas suas particularidades, definindo a sua identidade e envaidecendo a sua autoestima. Em termos econômicos, os investimentos poderão ser otimizados em setores mais adequados, fazendo com que os recursos naturais sejam utilizados conscientemente. É necessário chamar atenção para o fato de que a sustentabilidade pode ser abordada em diversas áreas, com ações pontuais ou complementares, atendendo a uma ou a muitas diretrizes do desenvolvimento sustentável. Como isso, espera-se afastar um entendimento comum de que o universo sustentável só se compromete com as funções práticas. Ressalta-se que as funções estéticas e simbólicas e os sentimentos envolvidos na relação usuário/ objeto são determinantes para a sustentabilidade. 
O caminho para a sustentabilidade tem como ponto de partida a inovação social, cultural e tecnológica "no âmbito do qual haverá lugar para uma multiplicidade de opções que correspondam às diferentes sensibilidades e oportunidades diversas" (MANZINI; VEZZOLI, 2002). Assim, "para ser sustentável, um sistema de produção, uso e consumo tem que ir de encontro das demandas da sociedade por produtos e serviços sem perturbar os ciclos naturais e sem empobrecer o capital natural" (MANZINI, 2008. p. 23).

Refletir as questões econômicas, sociais e ambientais; propor condições para um modo de vida mais sustentável e "separar as necessidades que amparam a vida das que destroem não deve ser visto como preocupação moral e sim como imperativo ecológico" (FRY, 2009. p. 61). A mudança de comportamento deve se pautar na reelaboração do consumo, afastando-se do fetiche e da tendência (WALKER, 2005). A prática do design deixou de se preocupar com a fabricação de coisas para compreender o contexto da vida das pessoas e, assim, satisfazê-las pela compreensão de histórias e narrativas de cenários futuros (SANDERS; STAPPERS, 2012).

Diante disso, acredita-se ser essencial compreender a afetividade, preservada na memória, para suscitar sentimentos que permitam uma relação mais sincera e duradoura entre os usuários e os artefatos. Acredita-se que essas questões precisem ser fomentadas no contexto de ensino e de aprendizagem para promover a conscientização no desenvolvimento de produtos que influenciem a responsabilidade ambiental.

\section{Pesquisa Pré-experimental no contexto de ensino e aprendizagem}

As diretrizes de projeto que visam os afetos e a memória positiva foram utilizadas na disciplina de projeto de produto 2, em um curso de Design. A disciplina foi ministrada pelas explanações sobre a bibliografia base, os exemplos de produtos, que pela configuração visual suscitam os vínculos afetivos e as diretrizes para identificar aspectos subjetivos, que visem aos afetos e à memória positiva. A disciplina foi ministrada com atividades: de identificação de objetos suscetíveis de despertar afetos e memória positiva, ligados à infância, aos hábitos e à cultura; das entrevistas realizadas com usuários; aplicação de questionários pelo google forms; do grupo de foco para discutir as ações realizadas; da análise da genealogia das formas; do estudo sobre a vida social dos objetos; reflexões sobre as diretrizes, que suscitam vínculos afetivos, bem como a identificação dos aspectos objetivos e subjetivos para a sustentabilidade.

A compreensão sobre a relevância dos artefatos na vida das pessoas foi realizada por: entrevistas entre os estudantes participantes e com pessoas que frequentavam a praia; produção de painéis que demonstraram objetos que suscitassem os afetos e a memória positiva (Figura 02). 


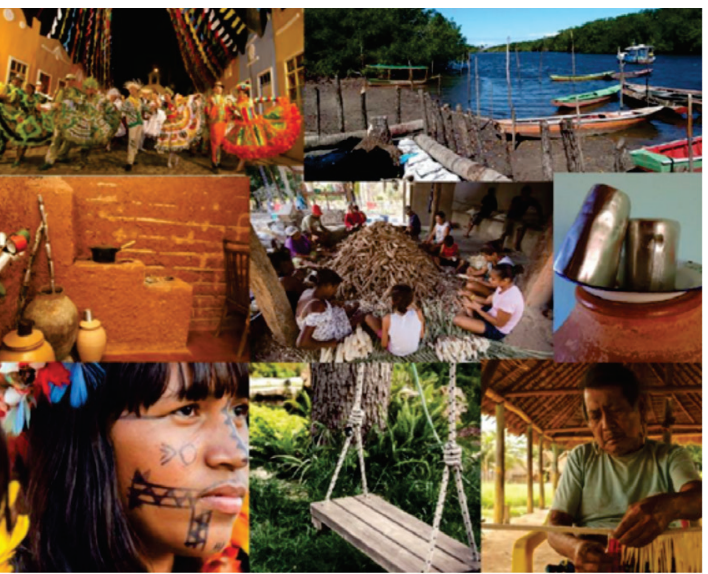

Fig 2. Painel sobre aspectos visuais que podem suscitar afetos e memória positiva, desenvolvido por um dos participantes | Fonte: Autor (2020)
Fig 4. Geração de ideias de um dos participantes para desenvolver um utilitário de mesa para degustar caranguejo Fonte: Autor (2020)

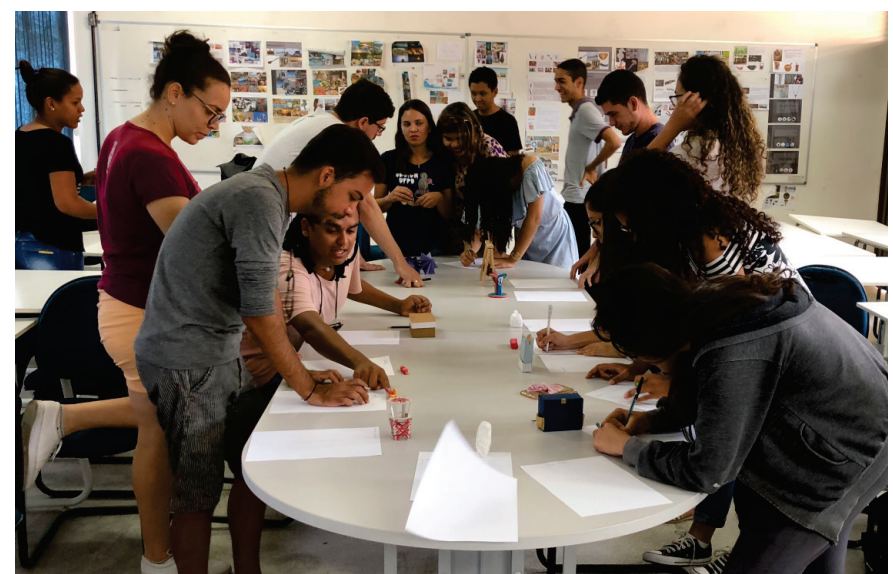

Fig 3. Discussões em grupo durante a aula | Fonte: Autor (2020)

Esses painéis foram expostos e discutidos em grupo. Em seguida, foi desenvolvida a análise da genealogia da forma e o estudo sobre a biografia dos objetos (Figura 03). A genealogia da forma foi formulada com base nas alterações da configuração visual ao longo do tempo, sendo identificado o que se manteve no objeto e motivos pelos quais não houve mudança. Pela biografia dos objetos, foi possível identificar a relevância daquele objeto na vida do usuário e as suas modificações do contexto.

Com a análise dos dados recolhidos foi possível gerar ideias, realizar discussões, analisar, refinar, gerar pequenos modelos de estudos físicos e indicar uma proposta final que contemplasse a oportunidade de design descrita no início do projeto (Figura 04).

De acordo com as fases, os estudantes desenvolveram painéis que demonstraram os objetivos do trabalho, a execução do roteiro de trabalho e a proposta do produto. Para concluir a pesquisa pré-experimental foi disponibilizado um questionário com questões abertas e fechadas.

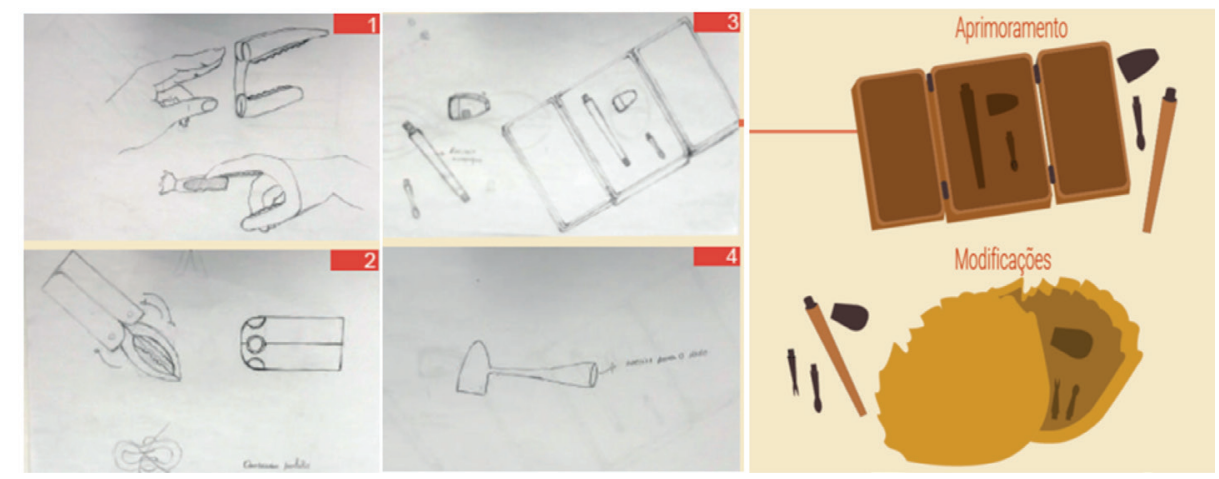




\section{Resultados e Discussões}

Os resultados foram analisados a partir da interpretação dos painéis produzidos pelos estudantes e pelas respostas aos questionários.

Os painéis demonstraram o caminho do projeto desenvolvido, a geração de ideias e a proposta do modelo final. Destaca-se o desenvolvimento dos projetos de um utilitário de mesa para degustar caranguejo (Figura 05), de uma bolsa de praia, que disponibiliza espaço adequado para objetos pessoais e conservação térmica de alimentos e bebidas (Figura 06) e de chuveiros público para praia (Figura 07).

Os projetos necessitam de ajustes com relação à configuração e às especificações de materiais e processos de fabricação. No entanto, é possível identificar aspectos culturais relevantes aos usuários, aparência visual simples, reforço de hábitos locais, utilização de materiais característicos da região, questões de familiaridade e de pertencimento e a possibilidade de suscitar afetos e memórias positiva.

Os questionários foram analisados quantitativamente, com base nas respostas conferidas na escala Likert: 1 correspondendo ao nível de satisfação mínimo e 5 indicando o nível de satisfação máximo e uma análise qualitativa, de acordo com as respostas abertas.

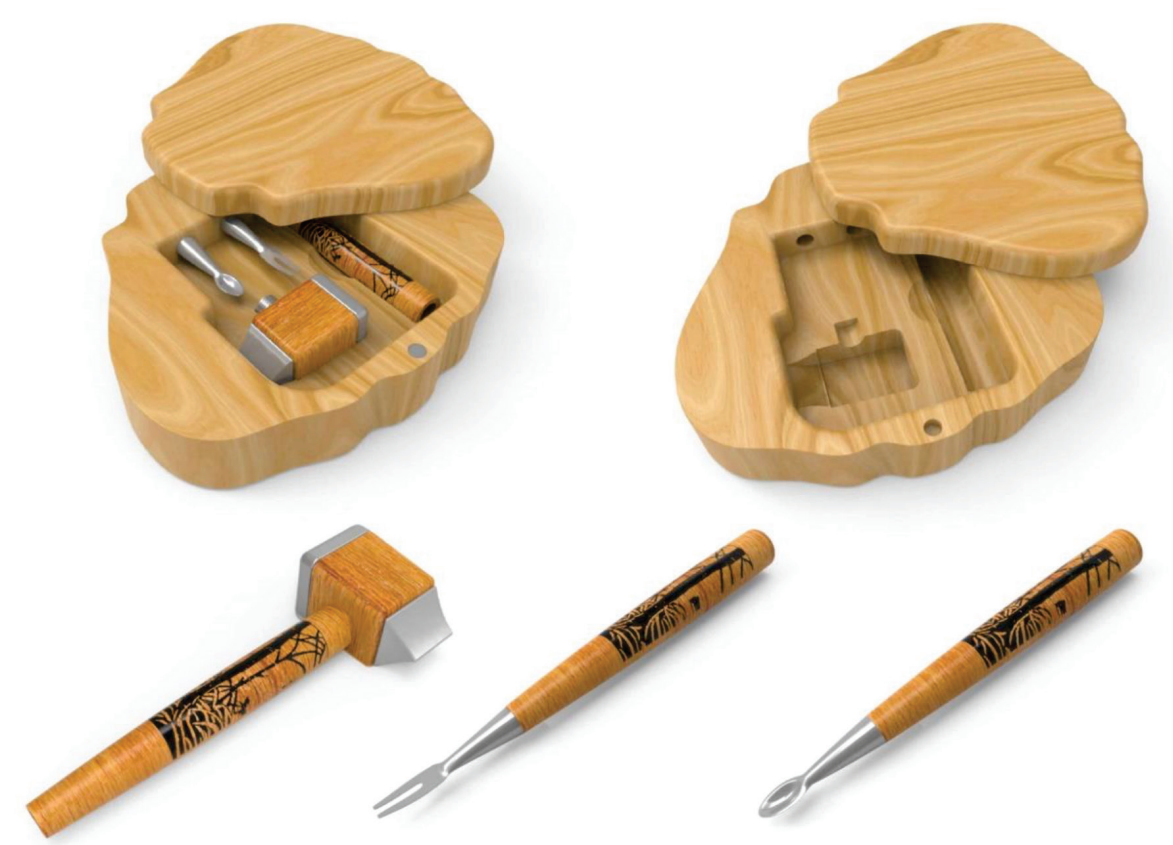

Fig 5. Projeto de um utilitário de mesa para degustar caranguejo

Fonte: Autor (2020) 


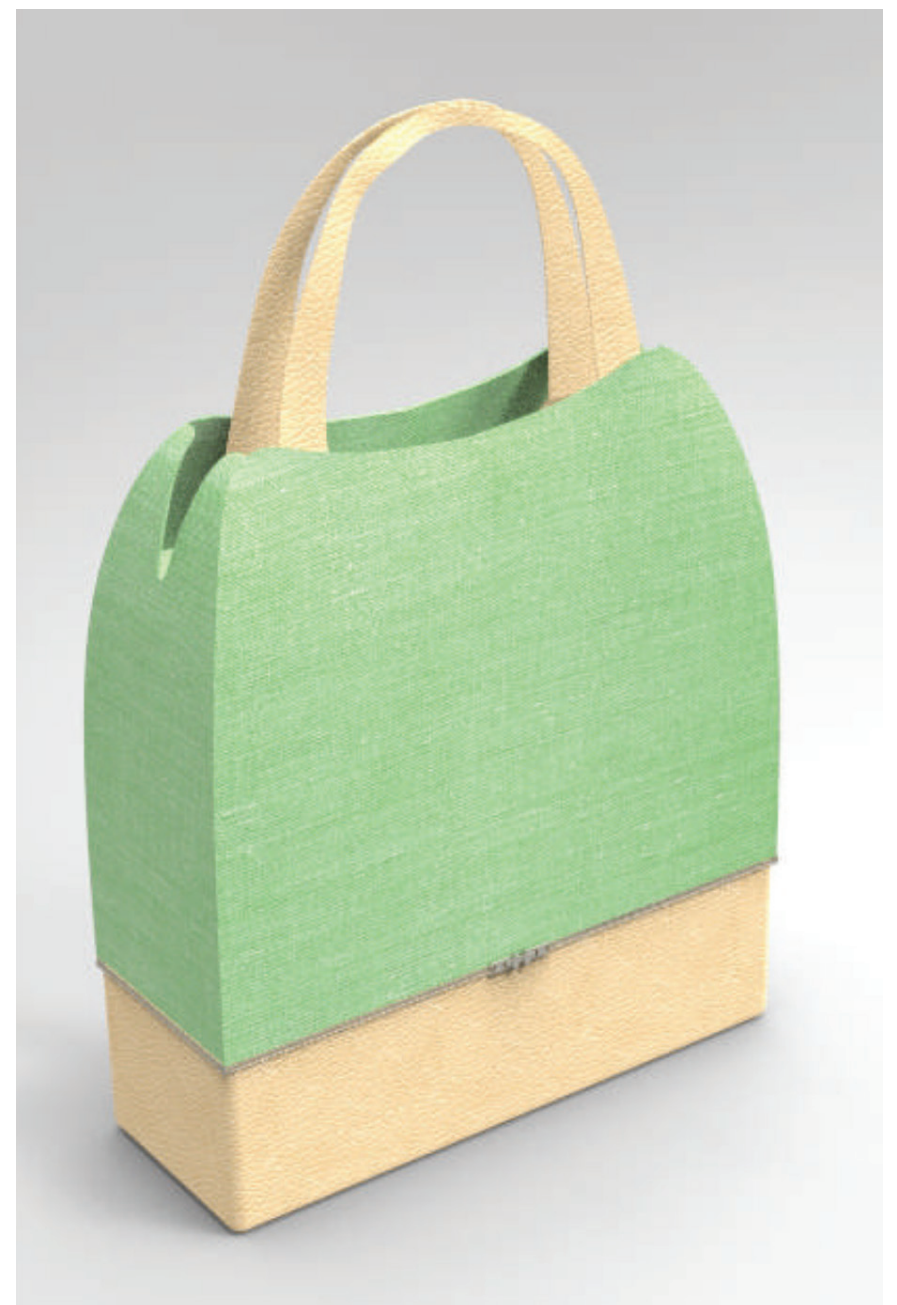

Fig 6. Projeto de bolsa de praia, que disponibiliza espaço adequado para objetos pessoais e conservação térmica de alimentos Fonte: Autor (2020)

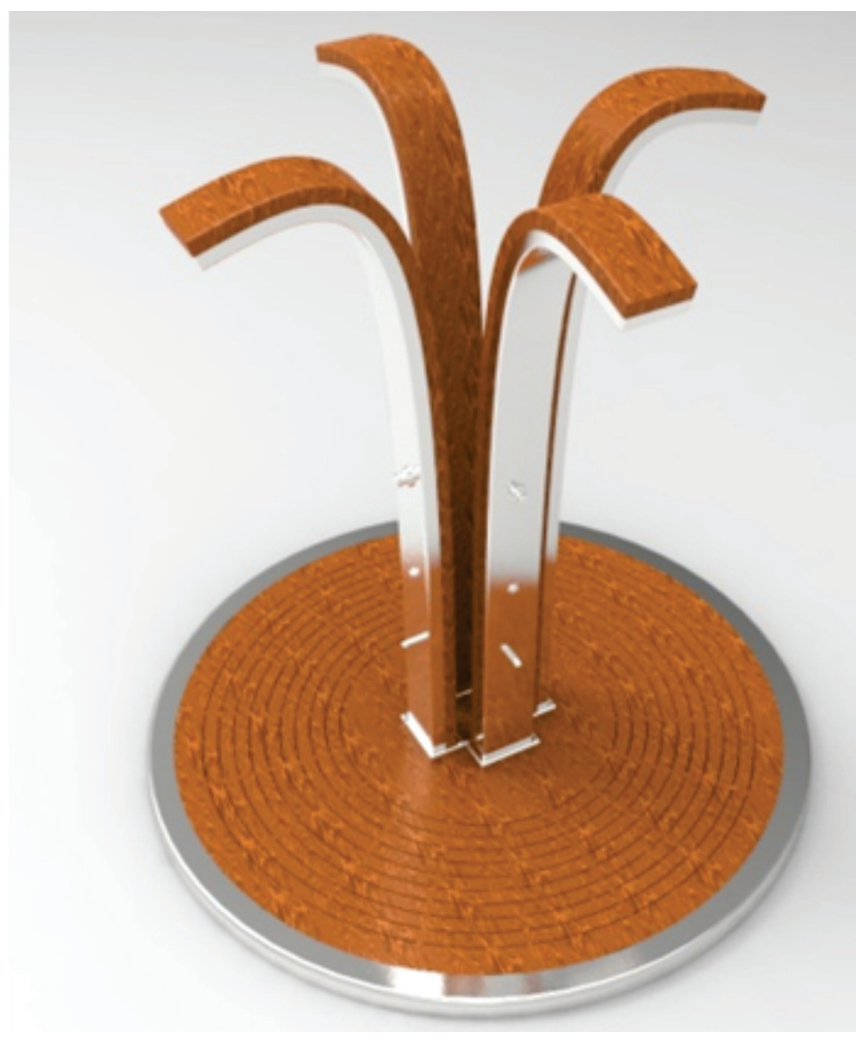

Fig 7. Projeto de chuveiros público para praia Fonte: Autor (2020)

A primeira questão avaliou as experiências de projetos anteriores. As respostas indicaram que 5\% apresentaram grau de satisfação como 2; $50 \%$ indicaram 3 como grau de satisfação; $35 \%$ indicaram 4 como grau de satisfação e $10 \%$ indicaram 5 como grau de satisfação (Figura 08).

GRAU $4 \quad 35 \%$

GRAU $3 \quad 50 \%$

Fig 8. Respostas ao grau de satisfação com relação às experiências anteriores no desenvolvimento de projeto Fonte: Autor (2020)
GRAU $2 \quad 5 \%$

GRAU $1 \quad 0 \%$ 
As experiências anteriores são avaliadas como medianas na sua maioria e, de acordo com os comentários, relacionam-se com a falta de clareza sobre os métodos; ausência de orientações sobre o processo; os métodos não eram seguidos; as questões sobre a sustentabilidade relacionada aos afetos e a memória tinha sido desconsideradas. A seguir são apresentados alguns comentários:

De forma resumida: um pouco limitado e falta de auxílio que pudesse direcionar com mais clareza o resultado final.

Sempre foi um processo muito mecânico. Não havia atenção para a questão da sustentabilidade emocional no desenvolvimento do projeto (comentários de alguns participantes).

Em seguida, foram questionados sobre a experiência atual. 55\% apontaram grau de satisfação 5; 30\% indicaram grau 4, 10\% indicaram nível 3 e $5 \%$ apresentaram grau de satisfação 1 (Figura 09).

Respostas relacionadas ao grau de satisfação com o DOM

Questionários respondidos pelos alunos da UFPB

GRAU $5 \quad 55 \%$

GRAU $4 \quad 30 \%$

GRAU $3 \quad 10 \%$

GRAU $20 \%$

GRAU $15 \%$

Fig 9. Respostas ao grau de satisfação com relação ao DOM

Fonte: Autor (2020)

Verifica-se que o grau de satisfação com experiência de projeto desenvolvida foi satisfatória. As respostas que indicaram os níveis 1 a 3 são referentes à exigência do cumprimento das etapas e quantidade de ações que tiveram que ser executadas. A seguir são evidenciados alguns comentários: 
Não gostei, foi pouco tempo e não consegui desenvolver bem.

Cansativo. Embora que as tantas dinâmicas tenham sido boas para o desenvolvimento deste projeto, com o tempo tornou-se monótonas e repetitivas. Talvez parte tenha sido pelo período reduzido de tempo. (participantes que indicaram grau de satisfação como sendo 1 e 3)

Em contrapartida, a maior parte ficou motivada e redigiu comentários positivos:

Tive um pouco de dificuldade no início até me adaptar ao processo projetual. Nunca havia trabalhado com a questão afetiva dessa forma.

Foi mais interessante, pois trouxe uma forma diferente de se projetar e trazer memórias afetivas positivas e expressividade cultural.

Foi uma experiência bem melhor que as anteriores.

Foi o melhor projeto. A forma como foi desenvolvido com dinâmicas, sempre produzindo em sala. (participantes que indicaram grau de satisfação como sendo 4 e 5).

O projeto desenvolvido ressaltou que os aspectos subjetivos, tais como estética, simbologia e sentimentos devem ser considerados como uma estratégia para estimular atitudes reflexivas orientadas à sustentabilidade. $\mathrm{Na}$ terceira questão foi abordada a relação do projeto desenvolvido com a sustentabilidade. $80 \%$ dos participantes afirmaram compreender a relação do projeto a sustentabilidade (Figura 10).

Respostas a pergunta: Houve algo sobre sustentabilidade que chamou sua atenção?

Questionários respondidos pelos alunos da UFPB

NÃO $20 \%$

SIM $80 \%$

Fig 10. Respostas sobre se algo chamou atenção com relação à sustentabilidade Fonte: Autor (2020) 
$80 \%$ dos participantes consideram que projeto desenvolvido demonstrou uma perspectiva sustentável relacionada aos vínculos afetivos e que foram motivados com relação à sustentabilidade, com respaldo nos afetos e na memória positiva. Destacam-se alguns comentários abaixo:

A maneira que me fez refletir sobre descarte e valorização do material.

A questão da durabilidade. Sobre o fato de não projetar produto com níveis de descarte fácil.

A questão do material e de como ele pode transmitir de forma ecologicamente correta os materiais procedentes da região.

A questão de torná-lo afetivamente sustentável.

Resgatar lembranças e laços afetivos e toda a interação envolvida no processo.

Por ser enfatizado a importância da ligação do usuário, com o produto, através de memórias afetivas, foi muito importante ter essa reflexão na hora de projetar.

É excelente por haver toda essa preocupação em estabelecer um laço afetivo como o usuário.

O ponto positivo foi usar a memória afetiva.

Indo por esse lado mais afetivo, acredito que possa agregar mais valor ao produto. Isso foi o principal ponto. (participantes que afirmaram ter adquirido novas informações sobre atitudes reflexivas orientadas a sustentabilidade).

A pré-experiência pode fazer com que participantes reflitam sobre modos de vidas vigentes, consumo, papel do design na sociedade atual e a relevância sentimental dos objetos para as pessoas. É importante ressaltar que a maior parte dos participantes afirmou que antes do projeto desenvolvido não tinham refletido sobre os vínculos afetivos estabelecidos entre usuários e objetos.

Desse modo, verifica-se que as diretrizes de projeto, visando afetos e memória positiva, possibilitaram reflexões sobre a sustentabilidade e os vínculos afetivos, como estratégia projetual para promover atitudes responsáveis no estudante. 


\section{Considerações Finais}

Parte-se do pressuposto de que o design deve ser empático, compreender o modo de vida das pessoas sem julgamento, reconhecer as reais necessidades e desejos, refletir sobre a relevância dos objetos na vida das pessoas, os vínculos sentimentais e ter responsabilidade sobre o meio ambiente.

Neste trabalho foram feitas considerações sobre os aspectos subjetivos relacionados aos vínculos afetivos. Observou-se que, ao longo do tempo, as ações projetuais passaram a abranger muito mais do que os aspectos práticos, como forma, materiais, funções e produção. Além desses, foram incluídos os aspectos social, cultural e ambiental como preocupações no desenvolvimento do projeto, possibilitando que o design se aproximasse das pessoas, da cultura e da sustentabilidade. Desse modo, visualiza-se que o design pode se concretizar como um trabalho colaborativo, para que as necessidades das pessoas e a sustentabilidade sejam alcançadas concretamente.

Materiais de baixo impacto ambiental, eficiência energética, qualidade e durabilidade dos materiais, modularidade, reutilização e reaproveitamento são ações que reconhecidamente visam a sustentabilidade. Observa-se que os aspectos objetivos são amplamente difundidos, tanto no âmbito acadêmico quanto no industrial. Contudo, acredita-se que os aspectos subjetivos, ou seja, significados, simbologia e sentimentos também podem auxiliar na conscientização ambiental.

Nessa perspectiva, foram analisados estudos que possibilitaram identificar atitudes relevantes para suscitar os vínculos afetivos entre os usuário e artefatos. Esses trabalhos possibilitaram a configuração de diretrizes que podem suscitar afetos e memória positiva. Tais diretrizes foram desenvolvidas em uma disciplina de projeto de produto e foram avaliadas com êxito pelos estudantes. A pré- experiência demonstrou que os participantes se sentiram motivados, que a maior parte desconhecia a possibilidade de incluir os vínculos afetivos como uma estratégia sustentável e que o trabalho colaborativo entre os participantes foi eficiente.

Como resultado, acredita-se que projetar juntos aos usuários e partes interessadas, ser empático e reconhecer significados e sentimentos dos artefatos poderá contribuir para atitudes reflexivas sobre a sustentabilidade na prática projetual em design. 


\section{Referências}

ARGUIN, Claudel. Emotional durability is the new sustainability, 2010. Dissertação (Mestrado em Design) - Design Northumbria University, Newcastle, UK., 2010. Disponível em: https://issuu.com/claudel/docs/claudels_thesis Acesso em: 11 set. 2015.

APPADURAI, Arjun. Commodities and the politics of value. In: The social life of things. Commodities in Social Perspective. Cambridge: University Press, 1986.

BAUDRILLARD, Jean. A sociedade de consumo. Lisboa: Edições 70, 1995.

BORJESSON, Kristina. The affective sustainability of objects: a search for causal connections: studies of theory, processes and practice related to timelessness as a phenomenon. 2006. Tese (Doutorado em Design) - University of the Fine Arts London, Londres, 2006.

BROWN, Tim. Change by design: how design thinking transforms organizations and inspires innovation. New York: HarperCollins, 2009.

BÜRDEK, Bernhard. História, teoria e prática do design de produtos. São Paulo: Edgard Blucher, 2006.

CARDOSO, Rafael. Design para um mundo complexo. São Paulo: Cosac Naify, 2012.

CHAPMAN, Jonathan. Emotionally durable design: objects, experience, empathy. London: Earthscan, 2005.

CHAPMAN, Jonathan. Routledge Handbook of Sustainable Product Design. New York: Routledge, 2017.

CSIKSZENTMIHALYI, M.; ROCHBERG-HALTON, E. The meaning of things: domestic symbols and the self. Cambridge University Press: Cambridge, 1981.

DAMÁSIO, António. O Sentimento de Si: O corpo, a emoção e a neurobiologia da consciência. Mem Martins: Publicações Europa América, 2004.

DAMÁSIO, António. E o cérebro criou o homem. São Paulo: Companhia das Letras, 2011.

DESMET, Pieter. Designing emotions. 2002. Tese. (Doutorado em Design) - Delft University of Technology, Delft, The Netherlands, 2002. Disponível em: https://studiolab.ide.tudelft. nl/studiolab/desmet/files/2011/09/thesis-designingemotions.pdf. Acesso em: 24 jun. 2017. HAINES-GADD, Merryn; CHAPMAN, Jonathan; LLOYD, Peter; MASON, Jon; Aliakseyeu, Dzmitri. Emotional Durability Design Nine: A Tool for Product Longevity, 2018. In: Sustainability, v. 10, n. 6, p. 1948 Jun. 2018.

FRY, Tony. Reconstruções: ecologia, design, filosofia. São Paulo: Edusp; 2009.

FUAD-LUKE, Alastair. Design activism: beautiful strangeness for a sustainable world. Londres: Earthscan, 2009.

KAZAZIAN, Thierry. Haverá a idade das coisas leves: design e desenvolvimento sustentável. São Paulo: Editora Senac, 2005.

KOPYTOFF, Igor. The cultural biography of things: commoditization as process. In The social life of things. Commodities in social perspective. Cambridge: University Press, 1986.

KRIPPENDORFF, KLAUS. Propositions of human-centeredness: A philosophy for design. In: DURLING, D; FRIEDMAN, K. (Eds.) Doctoral Education in Design: Foundations for future. Staffordshire: Staffordshire University Press, 2000. p. 55-63

KRIPPENDORFF, Klaus. The semantic turn: a new foundation for design. Boca Raton: Taylor \& Francis, 2006.

KRUCKEN, Lia. Design e território: valorização de identidades e produtos locais. São Paulo: Studio Nobel, 2009. 
KUBLER, George. A forma do tempo: observações sobre a história dos objetos. Lisboa: Vega, 1998.

MANZINI, Ezio; VEZZOLI, Carlo. O desenvolvimento de produtos sustentáveis. São Paulo: Editora da Universidade de São Paulo, 2002.

MANZINI, Ezio. Designing networks and metadesign. 2008. Disponível em: http://www.sustainable-everyday.net/manzini/. Acesso em: 25 fev. 2015.

MCDONAGH, Deana. Emotional sustainability. In: Routledge Handbook of Sustainable Product Design. New York: Taylor and Francis, 2017. p. 271-281.

PAPANEK, Victor. Design for the real world: human ecology and social change. Nova York: Phanteon Books, 1971.

PAPANEK, Vitor. The Green Imperative: Ecology and Ethics in design and Architecture. New York: Thames and Hudson Ldt, 1995.

PANTALEÃO, Lucas. Stuart Walker: a função estética sustentável: mediações entre arte, design e espiritualidade.Tese (Doutorado em Design) - Faculdade de Arquitetura Artes e Comunicação, Universidade Estadual Paulista, Bauru, 2017.

Robbins, Stephen. Comportamento organizacional. São Paulo: Pearson Prentice Hall, 2005.

RUSSO, Beatriz. Shoes, cars and other love stories: investigating the experience of love for products. 2010.Tese. (Doutorado em Design) - Delft University of Technology, Delft, 2010.

Sanders, E. B. N.; Stappers, P. J. Convivial Toolbox, Generative Research for the Front End of Design. Londres: BIS Publishers, 2014.

SOGUTI, Deniz; DESMET, Pieter; MERONI, Anna. Designing Emotions that last. Design United Exibition within Dutch Design Wee 2019. Disponível em: www.design-united.nl/critical-changes/designing-emotions-that-last. Acesso em: 23 março 2020.

SUDJIC, Deyan. A linguagem das coisas. Rio de Janeiro: Intrínseca, 2010.

THACKARA, Jonh. In The Bubble: Designing in a Complex World. Cambridge: The MIT Press, 2005. Van Krieken, B.; Desmet, P.; Aliakseyeu, D.; Mason, J. A sneaky kettle: Emotionally durable design. In: Proceedings of the 8th International Conference on Design and Emotion London, UK, p. 11-14 Set. 2012. Disponível em https://repository.tudelft.nl/islandora/object/ uuid:a6613b2b-6377-409b-a17d-5fac98871905 Acesso em: 20 ago 2018.

WALKER, Stuart. Designing Sustainability: making radical changes in a material world. Abingdon: Routledge, 2014. 